А. О. Германович, Е. В. Терешко

Белорусский государственный технологический университет

\title{
МЕТОДИКА ОБОСНОВАНИЯ ПАРАМЕТРОВ ТЕХНОЛОГИЧЕСКОГО ПРОЦЕССА ИЗМЕЛЬЧЕНИЯ СТВОЛОВОЙ ДРЕВЕСИНЫ В БАРАБАННОЙ РУБИЛЬНОЙ УСТАНОВКЕ
}

В последнее время переработка древесных отходов в топливную щепу при помощи мобильных рубильных машин приобретает важное значение для энергонезависимости республики. Существует множество технических характеристик отдельных агрегатов рубильных машин, среди которых зачастую сложно на стадии проектирования выбрать параметры составных агрегатов, а также определить значения основных показателей новой проектируемой мобильной рубильной машины. Измельчение древесинного сырья в щепу - сложный процесс, зависящий от различных факторов. Факторы, определяющие процесс резания древесины, могут относиться как к древесному сырью, так и к режущему органу рубильной машины. Изучение процесса резания древесины усложняется не только из-за наличия большого числа этих факторов, но и в связи с возможностью многочисленных их сочетаний. Эти комбинации создают различные условия для изменения параметров щепы. Чтобы установить степень и характер влияния этих факторов на процесс резания древесины, нужен общий для них критерий. Таким критерием избирают обычно величину усилия (или мощности) резания с учетом качества обработки и величину производительности. Порода древесины и ее физико-механические свойства оказывают существенное влияние на процесс измельчения древесного сырья в щепу, усилие резания и расход энергии. Величина скорости резания оказывает влияние на чистоту среза и качество щепы. Также существенное влияние оказывает площадь среза древесного сырья, которая при проведении проектных расчетов не всегда будет сопоставима с площадью простых фигур.

Ключевые слова: биоэнергетика, измельчение, мощность резания, рубильная машина, щепа.

Для цитирования: Германович А. О., Терешко Е. В. Методика обоснования параметров технологического процесса измельчения стволовой древесины в барабанной рубильной установке // Труды БГТУ. Сер. 1, Лесное хоз-во, природопользование и перераб. возобновляемых ресурсов. 2021. № 1 (240). С. 118-125.

\section{A. O. Hermanovich, Ye. V. Tereshko \\ Belarusian State Technological University \\ METHODOLOGY JUSTIFICATION PROCESS PARAMETERS GRINDING STEM WOOD IN THE DRUM CHIPPER}

Recently, the processing of wood waste into wood chips using mobile chippers has become important for the country's energy independence. There is a wide variety of technical characteristics of individual units of chippers, among which it is often difficult to select the parameters of composite units at the design stage and also determine the values of the main indicators of a new designed mobile chipper. Chopping wood raw materials into wood chips is a complex process, depending on various factors. Factors that determine the process of cutting wood can relate to both raw wood and the cutting body of the chipper. The study of the process of cutting wood is complicated not only due to the presence of a large number of these factors, but also due to the possibility of numerous combinations thereof. These combinations create various conditions for changing chip parameters. To establish the degree and nature of the influence of these factors on the process of cutting wood, we need a common criterion for them. This criterion is usually chosen the magnitude of the effort (or power) cutting, taking into account the quality of processing and the value of productivity. Wood species and its physical and mechanical properties have a significant impact on the process of grinding wood raw materials into chips, cutting force and energy consumption. The value of the cutting speed affects the cleanliness of the cut and the quality of the chips. The cutting area of wood raw materials also has a significant effect, which, when carrying out design calculations, will not always be comparable with the area of simple figures.

Key words: bioenergetics, shredding, cutting power, chipper, chips.

For citation: Hermanovich A. O., Tereshko E. V. Methodology justification process parameters grinding stem wood in the drum chipper. Proceedings of BSTU, issue 1, Forestry. Nature management. Processing of Renewable Resources, 2021, no. 1 (240), pp. 118-125 (In Russian). 
Введение. На сегодняшний день на лесозаготовительных предприятиях республики применяется широкий спектр мобильных рубильных машин, предназначенных для производства топливной щепы, выпускаемых как на отечественных, так и на зарубежных заводах. В процессе создания новой самоходной рубильной машины инженеры-конструкторы сталкиваются с проблемой выбора и обоснования параметров технологического оборудования и самоходного шасси [1-3].

Основная часть. Мобильная рубильная машина представляет сложную конструкцию взаимосвязанных между собой узлов и механизмов. Основным элементом машины является рубильная установка (рис. 1), благодаря которой из древесного сырья получается щепа. Так, древесное сырье загружается на подающий транспортер 1 , уплотняется прижимным вальцом 2 и подается к рубильному барабану 3 , где посредством контрножа 4 , резцов 5 и сита 6 , измельчается до нужных размеров в щепу. Полученная щепа при помощи винтового конвейера 7 перемещается к вентилятору 8 , который и выдувает ее по щепопроводу 9 к месту складирования. Все эти механизмы рубильной установки через механические (барабан, вентилятор, винтовой конвейep) и гидравлические (подающий транспортер, прижимной валец) передачи приводятся в действие от силовой установки (двигателя) [1, 4-7].

Мощность силовой установки в процессе проектирования рубильной машины определяет дальнейшую эффективность ее работы, связанную с производством щепы. Мощность привода рубильной установки равна сумме потерь мощности (энергозатрат) в основных ее механизмах:

$$
N=N_{1}+N_{2}+N_{3}+N_{4}+N_{5},
$$

где $N_{1}-$ мощность, затрачиваемая на привод подающего транспортера, Вт; $N_{2}$ - мощность, затрачиваемая на привод прижимного вальца, Вт; $N_{3}\left(N_{\text {рез }}\right)$ - мощность, затрачиваемая непосредственно на процесс измельчения древесного сырья в щепу, Вт; $N_{4}-$ мощность, затрачиваемая на привод винтового конвейера, Вт; $N_{5}$ - мощность, затрачиваемая на выброс щепы через щепопровод, Вт.

Мощность силы (резанья) $N_{\text {рез}}$, приложенной к вращающемуся телу (ножевому барабану), равна произведению вращающего (крутя-

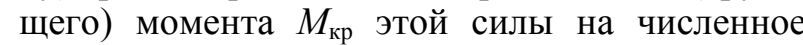
значение угловой скорости $\omega$ тела $[8$, с. 279].

$$
N_{\text {рез }}=M_{\text {кр }} \omega \text {, }
$$

где $M_{\text {кр }}-$ крутящий момент, $\mathrm{H} \cdot \mathrm{M} ; \omega-$ угловая скорость ножевого барабана, рад/с.

Крутящий момент определяется следующим образом $[8$, с. 279]:

$$
M_{\text {кр }}=F_{\mathrm{p}} R,
$$

где $F_{\mathrm{p}}$ - среднее усилие резания на ножевом барабане, $\mathrm{H} ; R$ - радиус ножевого барабана, м.

Угловая скорость ножевого барабана, выраженная через количество оборотов вращения барабана, определяется следующим образом [8, с. 188]:

$$
\omega=2 \pi \frac{n}{60}=\frac{\pi n}{30},
$$

где $n$ - число оборотов, совершаемых барабаном за время $t$, об/мин.

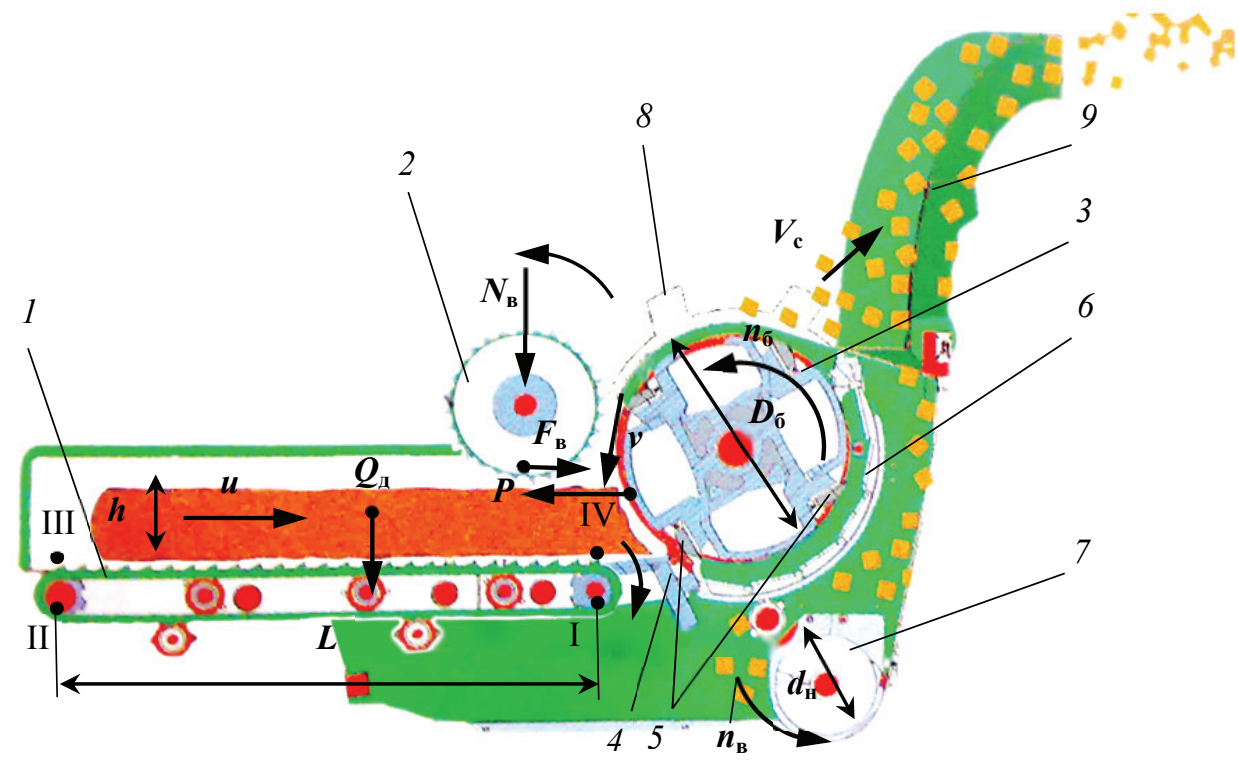

Рис. 1. Расчетная схема рубильной установки:

1 - подающий транспортер; 2 - прижимной валец; 3 - барабан; 4 - контрнож;

5 - резцы; 6 - сито; 7 - винтовой конвейер; 8 - вентилятор; 9 - щепопровод 


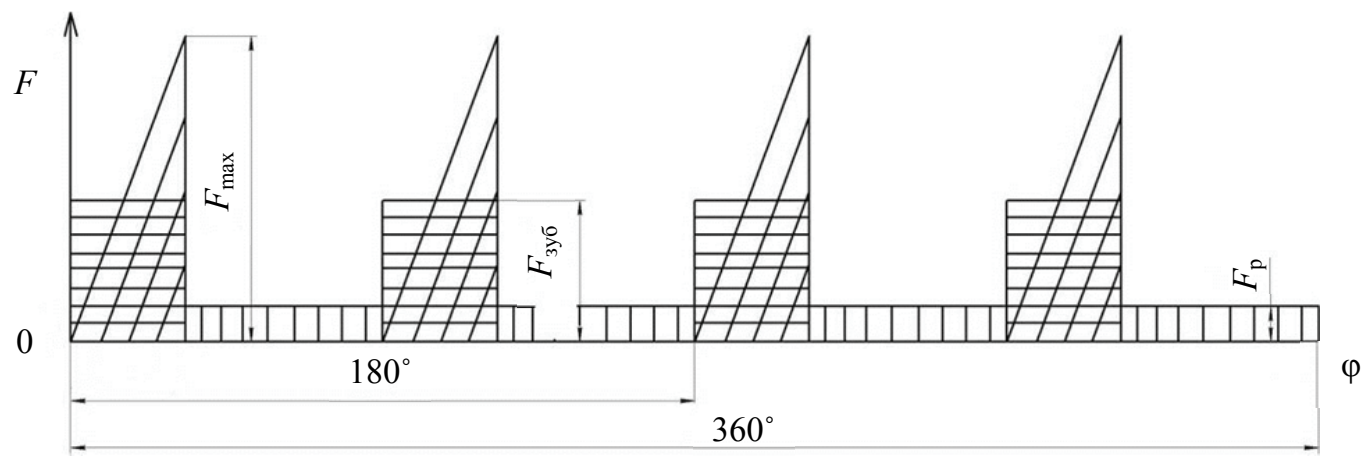

Рис. 2. Схема сил резания при измельчении древесины в щепу

Подставив выражения угловой скорости (4) и крутящего момента (3) в формулу мощности резания (2), получим:

$$
N_{\text {peз }}=F_{\mathrm{p}} R \frac{\pi n}{30} .
$$

С учетом проведенных ранее исследований рядом других ученых в области энергонасыщенности процесса резанья $[9$, с. $505 ; 10,11]$ можно заметить, что данная зависимость не учитывает такие факторы, как коэффициент трения древесины о барабан $\mu_{6}$ и КПД передаточного механизма ๆ. По этой причине будет логично учесть данные факторы. В результате формула мощности измельчения древесины в щепу при помощи рубильного барабана примет вид:

$$
N_{\mathrm{pes}}=\frac{F_{\mathrm{p}}\left(1+\mu_{\tilde{\sigma}}\right) R \frac{\pi n}{30}}{\eta}=F_{\mathrm{p}}\left(1+\mu_{\tilde{\sigma}}\right) R \frac{\pi n}{30 \eta},
$$

где $\mu_{6}-$ коэффициент трения древесины о барабан $\left(\mu_{\sigma}=0,2-0,5\right) ; \eta$ - КПД передаточного механизма $(\eta=0,95)$.

Для получения щепы в рубильных машинах применяется вид резания в торец. В процессе резания к резцу прикладывается усилие $F$, величина которого зависит от сопротивления резанию. Значение сопротивления резанию рассчитать довольно сложно, так как оно определяется различными взаимосвязанными факторами, зависящими от формы резца, строения и физико-механических свойств древесины. В процессе измельчения резец внедряется в древесину и снимает передней режущей кромкой слой древесины, тем самым разрушая древесину, отделяя от ее общей массы частицу щепы. Одновременно резец давит на эту частицу и деформирует ее. С увеличением глубины внедрения давление на слой древесины возрастает, и под влиянием упругой деформации частица щепы отделяется от основной массы древесины, при дальнейшем внедрении отделяется следующий элемент щепы. Усилие резания $F$, которое при- ложено к резцу, в процессе измельчения древесины изменяется (рис. 2) [10]. Оно достигает максимума при внедрении на глубину и падает до наименьшего значения в момент отделения частицы щепы от основной массы древесины. Такое изменение усилий резания является основной причиной вынужденных колебаний рубильной установки.

По своей абсолютной величине усилие на резце равно равнодействующей всех сил сопротивления резанию, действующих на резец со стороны древесины (усилие на лезвии резца, нормальное давление и сила трения на передней и задней гранях резца).

При получении щепы надвигание производится одновременно с резанием, поэтому усилие резания на рубильном барабане $F_{\text {p можно }}$ определить по формуле Денфера [9, с. 503]:

$$
F_{\mathrm{p}}=K b h \frac{u}{v}
$$

где $K$ - коэффициент удельного сопротивления резанию, $\mathrm{H} / \mathrm{m}^{2}\left(2-3 \cdot 10^{6} \mathrm{H} / \mathrm{M}^{2}\right) ; b$ - ширина среза измельчаемого древесного сырья, м; $h$ - высота среза измельчаемого древесного сырья, м; $u$ - скорость подачи древесного сырья, м/с $(u=0,05-0,50 \mathrm{~m} / \mathrm{c}) ; v-$ скорость резания, м/с.

Коэффициент удельного сопротивления резанию $K$ состоит из следующих коэффициентов, учитывающих: $K_{\mathrm{c}}$ - угол резания; $K_{\text {д }}-$ породу древесины; $K_{\text {o }}$ - степень заострения режущих кромок резца; $K_{\mathrm{e}}$ - влияние толщины щепы на сопротивление резанию $\left(K_{\mathrm{e}}=1,25\right)$; $K_{\text {в }}$ - влияние влажности древесины на сопротивление резанию (табл. 1-4) [9, с. 274], и выражается следующим образом:

$$
K=K_{\mathrm{c}} K_{\text {д }} K_{\mathrm{o}} K_{\mathrm{e}} K_{\mathrm{B}} .
$$

Таблица 1

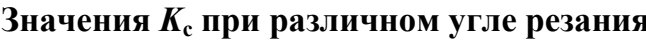

\begin{tabular}{|l|c|c|c|c|c|c|}
\hline Угол резания, град & 45 & 50 & 60 & 70 & 80 & 90 \\
\hline$K_{\mathrm{c}}, \mathrm{H} / \mathrm{mm}^{2}$ & 17,5 & 21 & 25 & 35 & 44 & 53 \\
\hline
\end{tabular}


Таблица 2

Значения $\boldsymbol{K}_{д}$ при измельчении различных пород древесины

\begin{tabular}{|l|c|c|c|}
\hline Порода дерева & $K_{\text {д }}$ & Порода дерева & $K_{\text {д }}$ \\
\hline Сосна & 1,0 & Береза & 1,25 \\
\hline Ель & 1,0 & Дуб & 1,7 \\
\hline Лиственница & 1,1 & Бук & 1,5 \\
\hline Осина & 0,85 & Липа & 0,8 \\
\hline
\end{tabular}

Таблица 3

Значения $K_{0}$ В зависимости

от числа часов работы ножей после заточки

\begin{tabular}{|l|c|c|c|c|c|c|c|c|}
\hline $\begin{array}{c}\text { Число } \\
\text { часов } \\
\text { работы }\end{array}$ & 0 & 1 & 1,5 & 2 & 3 & 4 & 5 & 6 \\
\hline$K_{0}$ & 1 & 1,2 & 1,25 & 1,3 & 1,4 & 1,5 & 1,6 & 1,7 \\
\hline
\end{tabular}

Таблица 4

Значения $K_{\text {в }}$ вависимости от влажности древесины

\begin{tabular}{|l|c|c|}
\hline \multicolumn{1}{|c|}{ Состояние древесины } & Влажность, $\%$ & $K_{\mathrm{B}}$ \\
\hline Очень сухая & $5-8$ & 1,1 \\
\hline Сухая & $10-15$ & 1,00 \\
\hline Воздушно-сухая & $20-30$ & 0,93 \\
\hline Свежесрубленная & $50-70$ & 0,89 \\
\hline Сырая (сплавная) & $>70$ & 0,87 \\
\hline
\end{tabular}

В формуле усилия резания (7) произведение ширины $b$ и высоты $h$ среза измельчаемого древесного сырья является проекцией площади среза: $b h=S$ (рис. 3). Ввиду сложной вогнутой овалообразной формы среза древесного сырья (рис. 4 и 5) ее проекция площади в силовых расчетах (теоретических исследованиях) ранее принималась упрощенно, как площадь загрузочного окна (рис. 3) с учетом его заполнения [9, с. 503]:

$$
S=b_{1} h_{1} k_{3},
$$

где $b_{1}$ и $h_{1}$ - ширина и высота загрузочного окна соответственно, м; $k_{3}$ - коэффициент заполнения сечения окна, зависящий от плотности укладки измельчаемого древесного сырья $\left(k_{3}=\right.$ $=0,45-0,99)$.

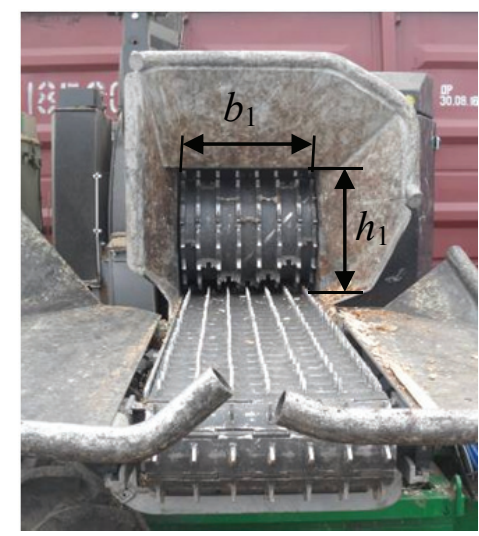

Рис. 3. Прямоугольная форма загрузочного окна

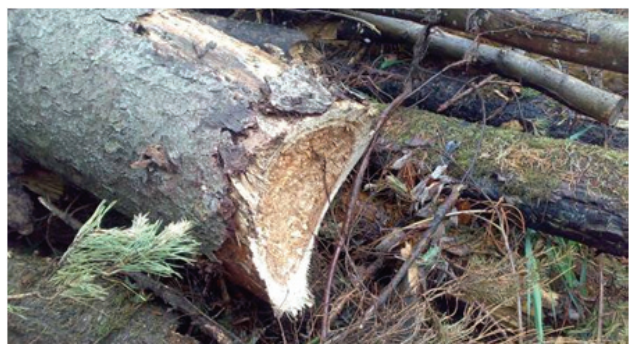

Рис. 4. Вогнутая овалообразная форма среза древесного сырья

Однако при измельчении в барабанных рубильных машинах стволовой древесины площадь среза будет представлять собой поверхность, образованную пересечением двух цилиндров $S_{\text {о }}$ - рубильным барабаном и древесным сырьем (рис. 5). Площадь такой поверхности определим при помощи вычисления поверхностного интеграла первого рода.

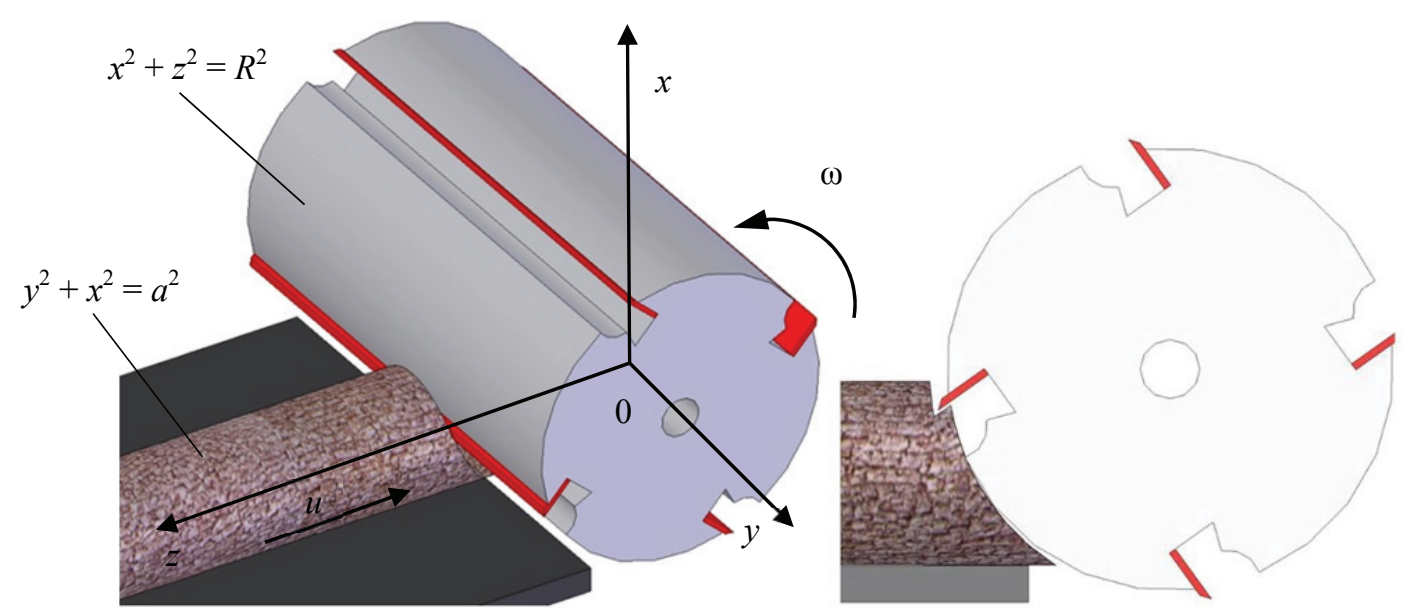

Рис. 5. Расчетная схема измельчения стволовой древесины в барабанной рубильной установке 
Вычисление поверхностного интеграла первого рода производится сведением к двойному интегралу $[12,13]$. Поверхностный интеграл обобщенное понятие криволинейного интеграла, при котором интегрирование происходит не по отрезку кривой, а по ограниченной поверхности.

Поверхность $Q$ задана уравнением $z=z(x, y)$, ее проекцией на плоскость $x O y$ является область $D_{x y}$, при этом функция $z=z(x, y)$ и ее частные производные $z_{x}^{\prime}(x, y)$ и $z_{y}^{\prime}(x, y)$ непрерывны в области $D_{\text {ху. }} f(x, y, z)-$ функция трех переменных, а поверхность $S_{\text {o }}$ - область интегрирования этой функции. При $f(x, y, z)$, равной единице, поверхностный интеграл равен площади поверхности. Тогда площадь среза $S_{\mathrm{o}}$ будет выражаться как:

$$
\begin{aligned}
& S_{\mathrm{o}}=\iint_{Q} d S_{\mathrm{o}}=\iint_{Q} f(x, y, z) d S_{\mathrm{o}}= \\
& =\iint_{D_{x y}} \sqrt{1+\left(z_{x}^{\prime}\right)^{2}+\left(z_{y}^{\prime}\right)^{2}} d x d y= \\
& =\left|\begin{array}{l}
x^{2}+z^{2}=R^{2} \\
z=-\sqrt{R^{2}-x^{2}} \\
z_{x}^{\prime}=\frac{x}{\sqrt{R^{2}-x^{2}}} z_{y}^{\prime}=0
\end{array}\right|=\iiint_{x^{2}+y^{2}=a^{2}} \frac{R d x d y}{\sqrt{R^{2}-x^{2}}}= \\
& =R \int_{-a}^{a} \frac{d x}{\sqrt{R^{2}-x^{2}}} \int_{-\sqrt{a^{2}-x^{2}}}^{\sqrt{a^{2}-x^{2}}} d y=4 R \int_{0}^{a} \sqrt{\frac{a^{2}-x^{2}}{R^{2}-x^{2}}} d x,
\end{aligned}
$$

где $R$ - радиус ножевого барабана (вращающегося цилиндра), м; $a$ - радиус древесного сырья в виде стволовой древесины (надвигающегося цилиндра), м.

Выражение (10) справедливо при $a \leq R$.

$$
a=d / 2 \text {, }
$$

где $d$ - диаметр древесного сырья (стволовой древесины), м.

Оценка точности разработанной математической зависимости площади среза $S_{\text {о ство- }}$ ловой древесины при измельчении в щепу производилась путем сравнения результатов теоретических (полученных при помощи разработанной математической зависимости) исследований с экспериментальными данными (рис. 6) [14, 15]. Рассматривался случай измельчения свежесрубленной стволовой древесины ели диаметром 0,35 м при помощи мобильной рубильной машины «Амкодор 2904», оборудованной рубильной установкой Kesla C645 с диаметром ножевого барабана 0,57 м. В результате относительная погрешность теоретических и экспериментальных значений не превысила $5 \%$.

Также производился сравнительный анализ теоретических значений, полученных при помощи разработанной математической зависимости, и расчетных значений площади среза $S_{\text {о }}$ стволовой древесины, полученных путем 3Dмоделирования в программном пакете автоматизированного проектирования КОМПАС-3D (рис. 7). В результате относительная погрешность $\beta$ теоретических и расчетных значений не превысила $0,5 \%$ и составила $0,0102 \%$. Полученные оценки погрешности позволяют сделать вывод об удовлетворительной степени сходимости результатов теоретических, экспериментальных, расчетных исследований и, следовательно, о приемлемости разработанной математической зависимости площади среза $S_{\text {o }}$ стволовой древесины при измельчении в щепу барабанной рубильной машиной.

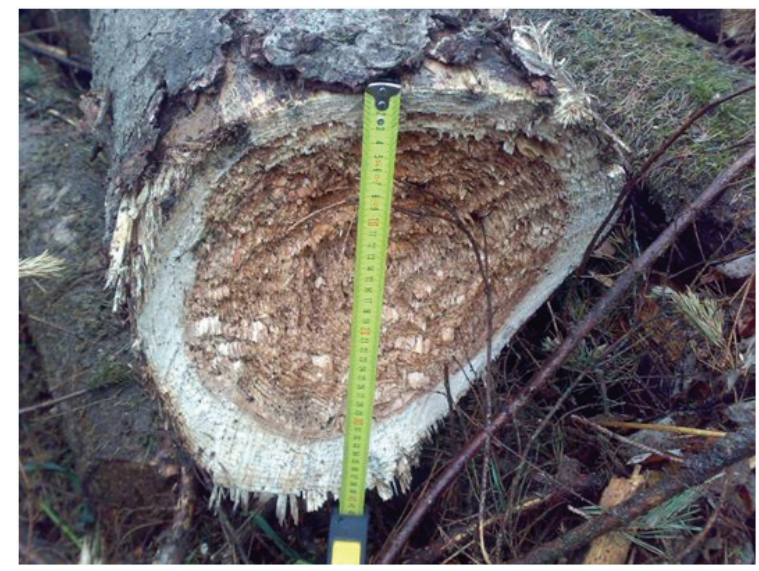

Рис. 6. Измерение параметров вогнутой овалообразной поверхности среза древесного сырья

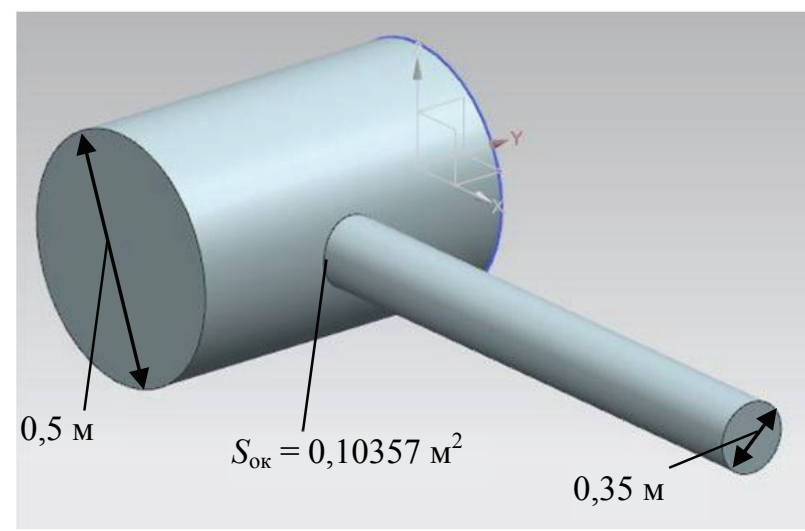

Рис. 7. 3D-модель пересечения двух цилиндров с вычисленной площадью поверхности среза

Также производился сравнительный анализ точности применяемых ранее упрощенных площадей поверхностей среза в виде круга - 
$S=\pi a^{2}$, прямоугольника - формула (9) и вогнутой овалообразной поверхности, полученной при помощи разработанной математической зависимости (10) (рис. 8). Менее приближенная к действительному значению площади среза является зависимость (9), принятая в виде упрощенной поверхности прямоугольника, относительная погрешность такой зависимости составила $17,1 \%$ при $k_{3}=0,99$. Относительная погрешность площади среза, принятой в виде упрощенной поверхности круга, составила 7,1\%. Таким образом, разработанная математическая зависимость (10) более точна на 7\% относительно формулы площади среза в виде круга и на $17 \%$ зависимости (9).

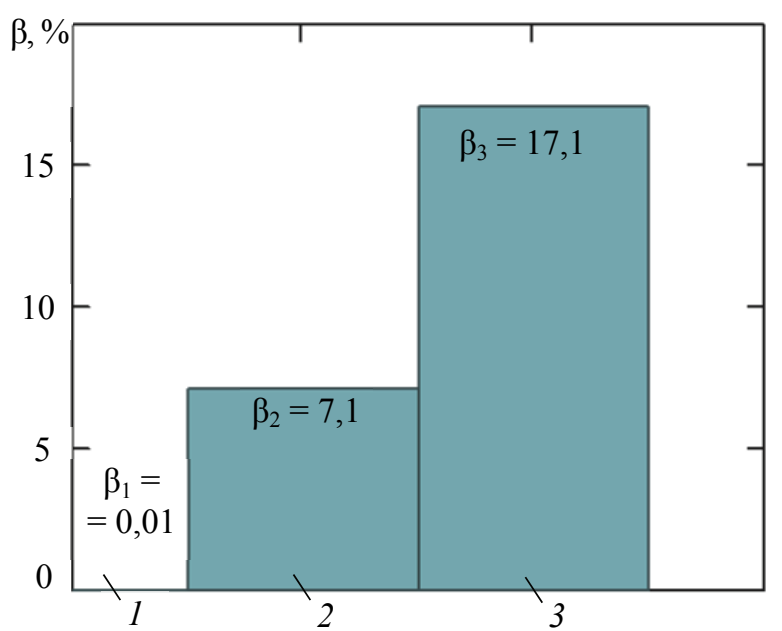

Рис. 8. Относительная погрешность площади среза: 1 - вогнутой овалообразной поверхности, полученной при помощи разработанной математической зависимости;

2 - принятой в виде упрощенной поверхности круга; 3 - принятой в виде упрощенной поверхности прямоугольника

Таким образом, формула (6), используемая для определения усилия резания на рубильном барабане, преобразуется в следующий вид:

$$
F_{\mathrm{p}}=K S_{\mathrm{o}} \frac{u}{v}
$$

Скорость резания ножевого барабана, выраженная через угловую скорость, определяется следующим образом [8, с. 192]:

$$
v=\omega R \text {. }
$$

Подставив выражения усилия резания (12), скорости резания (13), угловой скорости, представленную через количество оборотов вращения барабана (4), в формулу мощности резания (6) и проделав соответствующие преобразования, получим:

$$
\begin{gathered}
N_{\text {рез }}=K S_{\mathrm{o}} \frac{u}{v}\left(1+\mu_{\sigma}\right) R \frac{\pi n}{30 \eta}= \\
=K S_{0} \frac{u}{\omega R}\left(1+\mu_{\sigma}\right) R \frac{\pi n}{30 \eta}= \\
=K S_{\mathrm{o}} \frac{u}{\frac{\pi n}{30} R}\left(1+\mu_{\sigma}\right) R \frac{\pi n}{30 \eta}= \\
=\frac{K S_{0} u\left(1+\mu_{\sigma}\right)}{\eta} .
\end{gathered}
$$

Окончательно формула мощности резания (14) примет вид после подстановки выражения площади среза $S_{\text {о }}(10)$ :

$$
N_{\text {рез }}=\frac{4 R K u\left(1+\mu_{\sigma}\right)}{\eta} \int_{0}^{a} \sqrt{\frac{a^{2}-x^{2}}{R^{2}-x^{2}}} d x .
$$

При помощи данной формулы (15) были получены графические отображения влияний на мощность резания таких основных факторов, как радиус древесного сырья, радиус ножевого барабана, скорость подачи древесного сырья (рис. 9-11).

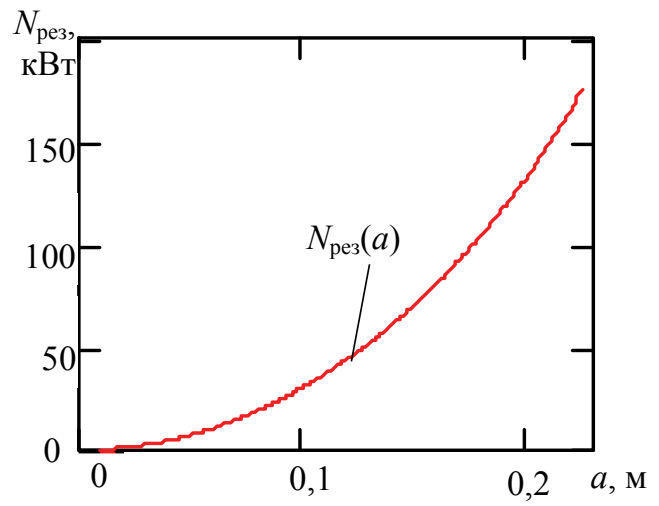

Рис. 9. Изменение мощности резания $N_{\text {рез }}$ в зависимости от изменения радиуса древесного сырья $a$

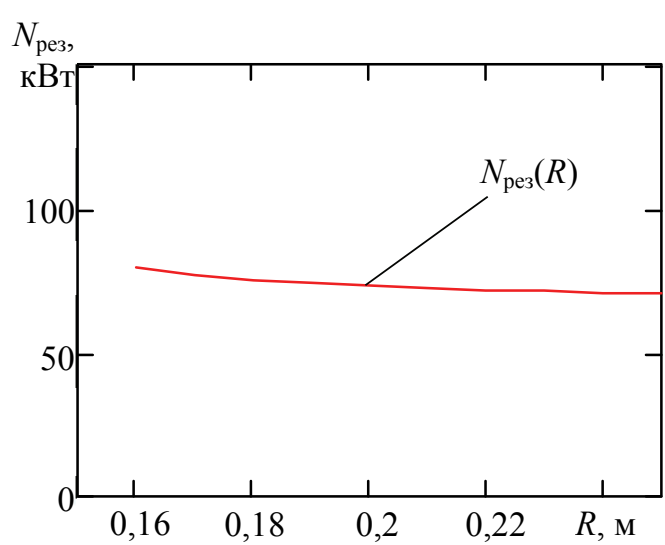

Рис. 10. Изменение мощности резания $N_{\text {рез }}$ в зависимости от изменения радиуса ножевого барабана $R$ 


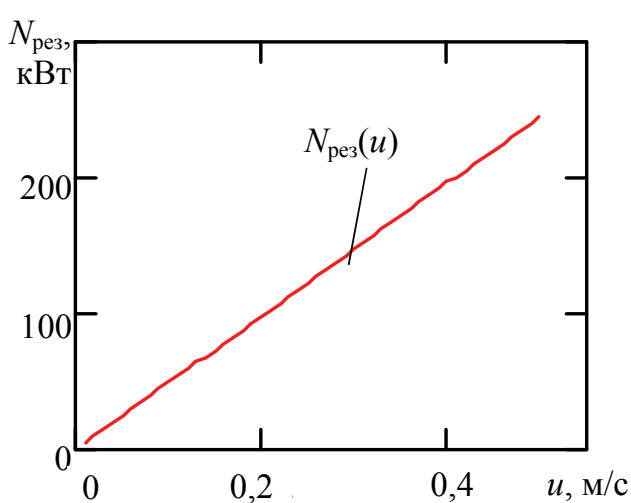

Рис. 11. Изменение мощности резания $N_{\text {рез }}$ в зависимости от изменения скорость подачи древесного сырья $u$

Проанализировав данные зависимости, можно установить, что при увеличении радиуса древесного сырья $a$ от 0,1 м до 0,225 м, мощность резания $N_{\text {рез }}$ увеличивается параболиче- ски до 174 кВт, а вот при увеличении радиуса ножевого барабана $R$ от 0,16 м 0,25 м (при соблюдения условия $a \leq R$ ) наблюдается снижение мощности резания $N_{\text {рез }}$ до 70,4 кВт. Также наблюдается рост мощности резания $N_{\text {рез }}$ при увеличении скорости подачи древесного сырья $u$.

Заключение. Процесс измельчения древесины является трудоемкой технологической операцией, по этой причине различные математические зависимости содержат ряд поправочных коэффициентов, что снижает точность расчетных величин $[9,10]$. Применение разработанной математической зависимости определения площади вогнутой овалообразной поверхности среза древесного сырья стволовой древесины, а также усовершенствование формулы мощности резания (измельчения) позволит увеличить точность проектных расчетов барабанных рубильных машин.

\section{Список литературы}

1. Германович А. О. Обоснование параметров мобильной рубильной машины на базе многофункционального шасси для производства топливной щепы: дис. ... канд. техн. наук: 05.21.01. Минск, 2015. 158 с.

2. Мохов С. П., Германович А. О. Анализ конструктивных особенностей рубильных машин // Труды БГТУ. 2011. № 2: Лесная и деревообраб. пром-сть. С. 40-44.

3. Германович А. О. Оценка параметров технологического и тягового модулей рубильной машины на самоходном шасси // Труды БГТУ. 2013. № 2: Лесная и деревообраб. пром-сть. С. 79-82.

4. Лой В. Н., Германович А. О. Влияние различных характеристик древесного сырья на энергонасыщенность рубильной машины // Труды БГТУ. 2012. № 2: Лесная и деревообраб. пром-сть. C. 21-24.

5. Германович А. О., Лой В. Н. Выбор мощности автономного двигателя рубильной машины // Новые материалы, оборудование и технологии в промышленности: материалы Междунар. науч.техн. конф. молодых ученых, Могилев, 17-18 нояб. 2011 г. Могилев, 2011. С. 145.

6. Влияние характеристик древесного сырья на энергозатраты рубильной машины с верхним выбросом щепы / А. О. Германович [и др.] // Материалы, оборудование и ресурсосберегающие технологии: материалы Междунар. науч.-техн. конф., Могилев, 19-22 апр. 2012 г.: в 2 ч. Могилев, 2012. Ч. 2. C. 13-14.

7. Facello A., Cavallo E., Spinelli R. Chipping machines: disc and drum energy requirements // Journal of agricultural engineering. 2013. Vol. XLIV (s2): e75. P. 378-380.

8. Белявский С. М. Теоретическая механика. М.: Высшая школа, 1965. 319 с.

9. Рахманов С. И., Гороховский К. Ф. Машины и оборудование лесоразработок. М.: Лесная промсть, 1967. $532 \mathrm{c}$.

10. Бершадский А. Л., Цветкова Н. И. Резание древесины. Минск: Вышэйшая школа, 1975. 303 c.

11. Вальщиков Н. М. Рубительные машины. СПб.: Машиностроение, 1970. 328 с.

12. Высшая математика. В 2 ч. Ч. 2 / В. М. Марченко [и др.]. Минск: БГТУ, 2014. 337 с.

13. Титаренко В. И., Выск Н. Д. Кратные, криволинейные и поверхностные интегралы. Теория поля. М.: МАТИ-РГТУ, 2006. 73 с.

14. Пижурин А. А., Розенблит М. С. Исследования процессов деревообработки. М.: Лесная пром-сть, 1984. 232 с.

15. Жуков А. В. Теория лесных машин. Минск: БГТУ, 2001. 640 с.

\section{References}

1. Germanovich A. O. Obosnovaniye parametrov mobil'noy rubil'noy mashiny na baze mnogofunktsional'nogo shassi dlya proizvodstva toplivnoy shchepy. Dis. kand. tekhn. nauk [Parametres substantiation of mobile chipper based on multifunctional chassis for wood chips production. Diss. cand. of engineer. sci.]. Minsk, 2015. 158 p. 
2. Mokhov S. P., Germanovich A. O. Analysis of the design features of chipping machines. Trudy $B G T U$ [Proceedings of BSTU], 2011, no. 2: Forest and Woodworking Industry, pp. 40-44 (In Russian).

3. Germanovich A. O. Estimation of parameters of technological and traction modules of the chipper on a self-propelled chassis. Trudy BGTU [Proceedings of BSTU], 2013, no. 2: Forest and Woodworking Industry, pp. 79-82 (In Russian).

4. Loy V. N., Germanovich A. O. Effect of various characteristics of raw wood on energy saturation of the chipper. Trudy BGTU [Proceedings of BSTU], 2012, no. 2: Forest and Woodworking Industry, pp. 2023 (In Russian).

5. Germanovich A. O., Loy V. N. Selection of power independent engine chipper. Materialy Mezhdunar. nauch.-tekhn. konf. molodykh uchenykh "Novyye materialy, oborudovaniye i tekhnologii v promyshlennosti" [Materials of the International scientific and technical conference of young scientists "New materials, equipment and technologies in the industry"]. Mogilev, 2011, p. 145 (In Russian).

6. Germanovich A. O., Loy V. N., Ariko S. Ye., Golyakevich S. A. Influence of characteristics of wood raw material to the energy chipper with overhead discharge chips. Materialy Mezhdunar. nauch.-tekhn. konf. molodykh uchenykh "Materialy, oborudovaniye i resursosberegayushchiye tekhnologii" [Materials of the International scientific and technical conference of young scientists "Materials, equipment and resource-saving technologies"]. Mogilev, 2012, part 2, pp. 13-14 (In Russian).

7. Facello A., Cavallo E., Spinelli R. Chipping machines: disc and drum energy requirements. Journal of agricultural engineering, 2013, vol. XLIV (s2): e75, pp. 378-380.

8. Belyavskiy S. M. Teoreticheskaya mekhanika [Theoretical mechanics]. Moscow, Vysheyshaya shkola Publ., 1965. 319 p.

9. Rakhmanov S. I., Gorokhovskiy K. F. Mashiny i oborudovaniye lesorazrabotok [Machinery and equipment lumbering]. Moscow, Lesnaya promyshlennost' Publ., 1967. 532 p.

10. Bershadskiy A. L., Tsvetaeva N. I. Rezaniye drevesiny [Wood cutting]. Minsk, Vysheyshaya shkola Publ., 1975. 303 p.

11. Val'shchikov N. M. Rubitel'nyye mashiny [Chippers]. St. Petersburg, Mashinostroyeniye Publ., 1970. $328 \mathrm{p}$.

12. Marchenko V. M., Asmykovich I. K., Borkovskaya I. M., Bochilo N. V., Gorbatovich Zh. N., Ignatenko V. V., Lovenetskaya E. I., Pyzhkova O. N., Solovieva I. F., Yakimenko A. A., Yanovich V. I., Yarotskaya L. D. Vysshaya matematika [Higher mathematics]. Minsk, BGTU Publ., 2014, part 2. 337 p.

13. Titarenko V. I., Vysk N. D. Kratnyye, krivolineynyye i poverkhnostnyye integraly [Multiple, curvilinear and surface integrals]. Moscow, MATI-RGTU Publ., 2006. - 73 p.

14. Pizhurin A. A., Rozenblit M. S. Issledovaniya protsessov derevoobrabotki [Woodworking research]. Moscow, Lesnaya promyshlennost' Publ., 1984. 232 p.

15. Zhukov A. V. Teoriya lesnykh mashin [The theory of forest machines]. Minsk, BGTU Publ., 2001. 640 p.

\section{Информация об авторах}

Германович Александр Олегович - кандидат технических наук, доцент, доцент кафедры лесных машин, дорог и технологий лесопромышленного производства. Белорусский государственный технологический университет (220006, г. Минск, ул. Свердлова, 13a, Республика Беларусь). E-mail: germanovich@belstu.by

Терешко Елена Владимировна - магистр физико-математических наук, ассистент кафедры высшей математики. Белорусский государственный технологический университет (220006, г. Минск, ул. Свердлова, 13а, Республика Беларусь). E-mail: tereshko@belstu.by

\section{Information about the authors}

Hermanovich Aliaksandr Olegovich - PhD (Engineering), Associate Professor, Assistant Professor, the Department of Logging Machinery, Forest Roads and Timber Production Technology. Belarusian State Technological University (13a, Sverdlova str., 220006, Minsk, Republic of Belarus). E-mail: germanovich@belstu.by

Tereshko Yelena Vladimirovna - Master of Physical and Mathematical Sciences, assistant lecturer, the Department of Higher Mathematics. Belarusian State Technological University (13a, Sverdlova str., 220006, Minsk, Republic of Belarus).E-mail: tereshko@belstu.by 